Bernhard Waldenfels

\title{
Comment on John Searle's The Construction of Social Reality
}

\begin{abstract}
This comment deals with some basic elements Searle uses in order to construct social reality, i.e. togetherness, we-intentionality and the distinction between institutional and brute facts. The commentator argues that Searle's theory tends to a partial biologism because lacking a sufficient concept of embodiment. Consequently 'pre-institutional facts' such as eating, copulating, working or torturing are systematically underdetermined. On the deontic level the theory relies on natural processes of conventional power. So the distinction between factual acceptance and acceptability is blurred by a sort of conformism, and one neglects the status of dissidents and victims whose belonging to the predominant 'we' remains highly dubious.
\end{abstract}

\section{Introduction}

John Searle is not one of those thinkers who need a lot of clearing up before one finds out what they are thinking about and how they are doing it. On the contrary, sometimes things may be all too clear to be true or too wellconstructed to be shared by others. Perfect construction would tend to include constructs of the author as well as constructs of the reader. In any case, for some of us, often addressed as "continentals', "society" or "reality" sound like catchwords which are overcharged with sense. These words are more like landmarks within an open landscape of thinking, and as such open paths or guides on Holzwege, but they do not have enough resemblance to bricks or foundation-stones to be used for new constructions of ideas. But even if presuppositions may considerably diverge from one reader to the other I will nevertheless try to prepare certain paths of discussion. First I shall give a more general comment on what John Searle is trying to do and on what seems to me worthwhile to discuss, and after that I shall open the debate by formulating some questions which bother me after reading his book on The Construction of Social Reality and which do not disappear after listening to his speech.

Analyse \& Kritik 20 (1998), S. 159-165 (C) Westdeutscher Verlag, Opladen 
Passing from philosophy of language through philosophy of mind to philosophy of society Searle arrives at a point where he has already been, at least in a certain sense. Speech acts in Austin's sense are institutional through and through. They can be institutional in a conventional way such as baptizing or getting married, or they can be institutional in a more general sense such as promising, asking or congratulating. Following the line of his speech act theory Searle does not work in the field of political philosophy analysing the establishment and the procedures of parliaments, governments, courts and so on, nor does he work as a philosopher of social science, focussing on what Schütz calls 'constructs of the second degree'. Instead he is interested in founding a philosophy of society. He takes an interest in scrutinizing sociability (in German: Geselligkeit) as such, including its institutional structure. Husserl would have called this kind of ontology 'regional ontology', in contrast to formal ontology (analysing something as something) and to the concrete ontology of the life-world which comprehends beings of every kind.

Searle's special approach to social philosophy, based on his former studies in speech acts and mental states, does not exclude the fact that he enters a domain which others before and around him explore under titles like soziales Handeln, sozialer Akt, Wechselhandlung, Interaktion, social behavior, ruleguided behavior, social world, Mitsein, soziale Verflechtung, entrelacs, intercorporéité, or response to the other, not to forget the complex of institution, Einrichtung, Stiftung and many similar topics. Although Searle likes to pretend that what others like Berger and Luckmann did is totally different from what he is doing himself, he frankly promises to solve a lot of traditional questions by using new tools. So Searle himself invites us to relate the solutions he offers to questions we inherited from old classics like Aristotle, Hobbes, Rousseau or Hegel and from more recent classics like Weber, Durkheim, Simmel or Mead - questions we are still discussing in different ways, referring e.g. to Mead or Schütz, to Habermas or Luhmann, to Merleau-Ponty or Levinas, to Bourdieu or Foucault. We should not stick to historical names which for Searle are more or less like Schall und Rauch, but we cannot refrain from adhering to the questions running under these and similar names, or in the end under our own names.

But let me come back to Searle's own endeavour. While developing his social ontology he tries to avoid two extremes. On the one hand he opposes a simple sort of biologism which reduces all institutional facts and rules to biological processes, on the other hand he attacks vehemently a radical kind of social constructionism (sometimes called 'idealism') which takes every form of reality to be socially constructed, including society itself. Thus avoiding the Scylla of biologism as well as the Charybdis of sociologism, he attempts to establish what one could call a sort of social ontology on the basis of social biology. In this context the question arises how institution-dependent 
social facts like money, marriage or football match institution-independent facts like eating, making love or walking, and how the gulf between both is bridged. This problem reminds us of the old definition of man as $\zeta \omega o \nu$

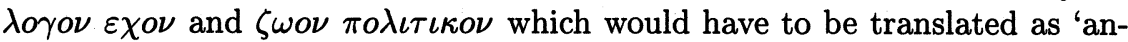
imal endowed with language' and 'animal living in institutions'. Now the 'apparatus' Searle uses in order to reconstruct social reality consists of four basic elements: imposition of functions (ultimately starting from brute physical facts) - collective intentionality (which allows for a common imposition of functions) - constitutive rules (by which $\mathrm{X}$ counts as $\mathrm{Y}$ ) - background abilities (as causal support of intentional states and rule-guided behavior). My following questions will mainly deal with these preconditions of sociality in its pre-institutional and institutional forms. They will start from the bottom, passing from collective intentionality through the analysis of rules and institutions up to deontic aspects such as acceptance and power. As to reality presupposed as such by the appeal to brute facts, I will only touch upon it.

Searle assumes that social reality originates from collective intentionality. Collective intentionality does not mean that the other's intentional state belongs to the representational content of my own intentional state (such that I know that you know that etc.), nor does it mean that intentional states are ascribed to a 'supermind', but rather that intentional states are shared by both of us. I do something as part of what we are doing, and you do the same. So I take part in your intentions, convictions and wishes and you take part in mine. This Ineinander of intentionalities is called we-intentionality. In a similar context Husserl speaks of a intentionale Gemeinschaft in order to indicate that the "cum-" of community, the 'being with', is mediated by sense intended by each member of the community. But we know how Husserl stumbled into the problem of solipsism, trying to show how even this togetherness is constitute-constituted by whom? By me.

(1) Here my first question arises. How does Searle come to terms with the constitution of togetherness, and how does he explain the common character of what is shared by each individual? How does he defend his special version of participative individualism? The answer Searle gives us sounds quite simple. He claims that collective intentionality has to be taken as a 'biologically primitive phenomenon'. The standard example he quotes consists in a pack of hyenas attacking a lion. There is no problem whatever. Each animal belonging to the same species collectivity is governed by genetic programs, instinctive regulations and a certain margin of learning, and the lion is included in the hyena program as typical prey. It needs only an appropriate Stimulus to create a common situation. All these biological preconditions remain on this side of the culture threshold. Now the examples taken from animal life are complemented by others taken from human life, e.g. the playing of an orchestra, a football game, a boxing match, court case, a cocktail party and so on. 
However, these examples do not demonstrate the biological character of these interactions because they take place on the other side of the culture threshold, being already governed by frames of cultured rules. If we stay either on this side or on the other side of the threshold which separates culture from nature, we can say nothing about passing this threshold, a process called Civilization, Cultivation or Moralization by Kant and others. In general, reflections on the genesis of culture circle around questions such as: $\pi \omega \varsigma \beta \iota \omega \tau \epsilon o \nu$ ? How should we live (and not only survive)? Or how to avoid that one human being threatens to kill the other? Hobbes famous saying homo homini lupus is not beyond doubt, but by comparing man with a certain animal species it points out the fact that the human species is not just another kind of animal species but rather a kind of 'non-fixed animal'. I wonder what Searle really wants to say when he stresses that "collective intentionality" belongs to the realm of biological facts. Does he mean that there is some collectivity to be found in animal life? This would be an old topic of social philosophy which evokes not only the aggressive behaviour of wolves, but also the peaceful and industrious life of ants. But this proves nothing unless collectivity as such, including human collectivity, is defined as biological. But that would mean silencing the above mentioned questions before they are posed. Searle mentions the street assault as an example of non-cooperative behaviour, but is this all that can be said about it? Does the victim belong to the agressor's 'prey world' in a similar way to how the lion belongs to the 'prey world' of hyenas? Does torturing belong to the mere realm of biology? It seems to me that there is a gap between mere biological and human sociality in all it's forms, and we unavoidably turn to a partial form of biologism if we neglect this.

(2) Similar problems arise when we analyse the concept of we-intentionality, by which collective intentionality is explained. We-intentionality, attributed to me as well as to you, means that I think in terms of 'we' and you do the same, without there being a substantial We, independent of the individuals' thinking in terms of 'we'. We are not we, but we behave as part of a we, and precisely this behaving as cannot be explained by the pure fact of belonging to a human group or to the human species as a whole, whereas it might indeed be explained in such a way in the case of animal society. Take a European or a Chinese man or woman. They both may have the sense of being member of mankind, thinking in terms of 'we human beings', nevertheless the sense of being (linguistically expressed or not) would differ from one person to the other.

Besides, the personal pronoun "we", used in Searle's explanation of collective intentionality, splits into an exclusive and an inclusive form, excluding or including the addressee. Searle's attribution of the we-intentionality to different individuals tells us nothing about the drawing of borderlines which divide what belongs to us and what belongs to others, constituting an in-group and 
an out-group. If the limits of we-groups were fixed by nature we would end at the dubious status of friends and enemies 'by nature' ( $\varphi v \sigma \epsilon \iota)$. However, appealing to nature is not something that happens by nature. I do not think that Searle really would say that it is, but I do not see how he excludes such highly ideological perspectives.

One intermediate remark. One could be inclined to fill in the gaps left open by a purely pre-institutional human biology by invoking institutional rules. But this expedient is excluded by the author's clear presupposition that establishing institutions by the collective imposition of functions and the collective recognition of status functions already presupposes the collectivity of a We. Ultimately, the capacity to make something symbolize something, which underlies language and every kind of institution, is considered to be a 'biological capacity' - which somewhat resembles the old vis dormitiva explaining sleeping by being able to sleep.

But let us now cross the cultural Rubicon and look back at social behavior from the other side, that is from the side of institutions. The central point is the distinction between constitutive rules generating institutional facts and regulative rules applied to pre-existing brute facts. I do not intend to question this well-known distinction as such, I only wonder whether the dichotomy exhausts what is going on in human social life, or whether on the contrary another gap now opens, or perhaps the same gap, now regarded not from the perspective of nature but from the perspective of culture. This leads to my third question.

(3) The difference between non-institutional and institutional social facts is explained as follows. Institutional facts like money, marriage or propriety are created by the collective imposition of functions to brute facts which seem to be otherwise unable to fulfill these functions by virtue of their own physical structure alone, and this is in opposition to eating, copulating, walking, fishing or torturing. Non-institutional social facts mean among other things: "The function of $\mathrm{X}$ is to $\mathrm{Y}$ ", whereas institutional facts take the standard form: "X counts as $\mathrm{Y}$ " (see Hobbes: we have to ask: "quid furtum dicendum est", De cive XIV, 17). But I wonder whether such brute facts, reduced to pure physical and biological structures, really exist at all in the field of human life. What may be characterized as simply pregiven on the level of artificial rules manifests itself on its own level as highly organized and structured, and is such in an artificial, contingent way, invented by human beings. As 'non-fixed animals' humans are forced to invent their own forms of life. Take eating customs, sexual practices, family structures, gender (often distinguished from sex), organisation of space and time, body techniques, styles of housing and clothing and so on. All these aspects of life may be more or less natural (as in the difference between the raw and the cooked), but they are never natural or physical through and through. Selective orders may well be called 
brute orders (Foucault) because there are sufficient reasons for their existence neither in nature nor in the existing culture, but they are certainly not brute facts. The selectivity of certain orders and the selection of a certain form of life can be naturally derived only if we presuppose that they serve no end but the survival of living beings and that they do this under conditions which allow only for one way of survival. In sum: so-called pre-institutional facts are systematically underdetermined, and therefore a partial biologism appears again.

(4) From the standpoint of phenomenological description I would like to ask if this underdetermination of culturally impregnated phenomena does not derive from the lack of an appropriate theory of body, wherein the body would function as 'transition-point' (Umschlagstelle) between nature and culture. Concepts like habit and habitualization, which belong to the fundamental equipment of practical philosophy and of modern social science point to a process of incorporation, (Einverleibung, Verkörperung) and of enculturation by practise. They suggest a concept of institution in the broader sense, not restricted to conventional rules. Searle approaches this problem when speaking of background abilities, but he withdraws from it when he loosens the Hintergrund from the ich kann of the agent and interprets the background in a pure causalistic way, passing from the participant's attitude to that of the observer.

Finally a few words on the 'deontic apparatus' by which Searle's theory turns to the normative and political aspects of social reality. Acceptance (or recognition) and power seem to me to be the key concepts which open the normative dimension of institutions. They are inherent to the logic of institutions. The creation of institutions by the collective imposition of functions includes the acceptance of the new status-function (e.g. a certain currency or certain political duties and rights) by those who create them. In addition, the creation of a new status-function in general depends on the conferring of some power (that is authorization, permission, enablement), and this institutional power differs from physical power (or violence) by its collective acceptance or recognition. Here two further questions arise.

(5) In my view this logic of norm and power tells us nothing about the genesis of sociality. Why? Because the collectivity of a We is presupposed by the establishment of institutions, which happens collectively. Consequently acceptance means, so to speak, collective self-acceptance, and enablement as Ermächtigung refers back to self-enablement. The 'deontic apparatus' is only added onto a brute, physical form of society. But this liberal story has a weak point. Because the limits, the mechanisms of inclusion and exclusion, inherent to 'brute' societies, are nowhere discussed, these limits are transferred into institutional societies without further examination. What about living in institutions which are at least partly imposed by others? What about living 
within an inhomogenous society which does not allow us to say simply 'we'? What about deviations from established rules or the status of dissidents? I do not postulate that every question like this should be fully discussed in one single book, but I do ask for the place left for discussing such crucial questions within such an ambitous logic of sociality and institutions.

(6) My last question starts from the well-known distinction between factual acceptance and intrinsic acceptability (or non-acceptability). Unfolding the logic of power, Searle ends with an natural process of creations and destructions of conventional power. A recent example Searle refers to is the collapse of the Soviet Empire. I skip the question to what extent this breakdown can be attributed to the pure withering of collective acceptance-although Berlin would be a good place to discuss it. What embarrasses me is the author's frequent shift from the third to the first person plural without any comment. Who is we? Phrases like "many of us think ..." or "everything we value in civilisation ..." sound like a confession of liberal faith. In general Searle follows Hume's path, evoking habits and traditions when questions of motivation arise. Throwing a side-glance at Hobbes he declares: “... we are in a state of nature all the time, but the state of nature is pricisely one in which people do in fact accept sytems of constitutive rules, at least nearly all the time." But what does that mean? Constitutive rules cover a lot of practices from the brand mark on the slave's body and the registration of the unemployed up to the political verdict against dissidents correctly formulated in their own language.

There are many other questions left, and we could discuss this theory more in its technical details. But doing so we should not forget the traditional questions which John Searle promises to solve with new instruments, and in the end we should be grateful to him for all the questions he provokes by his work. 